African Crop Science Journal by African Crop Science Society is licensed under a Creative Commons Attribution 3.0 Uganda License. Based on a work at www.ajol.info/ and www.bioline.org.br/cs DOI: http://dx.doi.org/10.4314/acsj.v24i3.2

\title{
HETEROSIS AND HERITABILITY ESTIMATES OF PURINE ALKALOIDS AND POLYPHENOLS IN COCOA
}

\author{
P.O. EFFA ${ }^{1,2}$, M.L. ONDOBO ${ }^{2}$, P.F. DJOCGOUE ${ }^{2,3}$ and N. NIEMENAK ${ }^{2}$ \\ ${ }^{1}$ Department of Biochemistry, Faculty of Science, University of Yaoundé I, P. O. Box 812, \\ Yaoundé, Cameroon \\ ${ }^{2}$ Laboratory of Plant Physiology, Department of Biological Sciences, Higher Teacher's Training College, \\ University of Yaoundé I, P. O. Box 47, Yaoundé, Cameroon \\ ${ }^{3}$ Department of Plant Biology, Faculty of Science, P. O. Box 812, Yaoundé, Cameroon
}

Corresponding author: peffafr@yahoo.fr

(Received 17 February, 2016; accepted 5 June, 2016)

\begin{abstract}
Cocoa (Theobroma cacao L.) is an important allogamous tropical tree crop, whose centre of diversity is considered to be in Central America. Dry cocoa beans from five cocoa clones, and their intercrossed hybrids were analysed based on the variation of alkaloids and polyphenolic compounds contents, in order to gain insights on the heterosis and broad-sense heritability. Polyphenols and alkaloids were analysed at $280 \mathrm{~nm}$ by HPLC, using a Photodiode Array Detector (PDA); while anthocyanins were separated with the SEP-PAK Vac 6cc $1000 \mathrm{mg}$ (waters) column and measured at $520 \mathrm{~nm}$ with a PDA. Dry cocoa beans displayed high content of purine alkaloids ( 2.1 and $8.8 \mathrm{mg} \mathrm{g}^{-1}$ for caffein and theobromine, respectively), and polyphenols ( 25 and $2978 \mu \mathrm{g} \mathrm{g}^{-1}$ for catechin and epicatechin, respectively). Among the five cocoa clones, SNK16 was the highest in purine alkaloid (caffein and theobromin) and flavanol (catechin and epicatechin); while T79/467 possessed the greatest quantity of cyanidin-3-galactoside and cyanidin-3-arabinoside. From all the parameters studied, anthocyanins (Cyanidin3-galactoside and cyanidin-3-arabinoside) exhibited the highest level of heterosis. Parental genotypes SNK16 and T79/467 showed good aptitudes for the combination of characters because their reciprocal hybrids F5 and F9, distinguished themselves by better levels of mid-parent heterosis values. Besides, the heritability value in strict sense of this Cyanidin-3-galactoside was very high. Absence of significant difference between genotypes, coming from reciprocal crossbreeding for Cyanidin-3-galactoside, suggests that this character in cocoa would be nuclear contrary to purine alkaloids and flavan-3-ols, where their transmission to offsprings can be stated as cytoplasmic.
\end{abstract}

Key Words: Caffein, catechin, Theobroma cacao

\section{RÉSUMÉ}

Le cacaoyer (Theobroma cacao L.) est une importante plante tropicale allogame originaire d'Amérique Centrale. Les teneurs en alcaloïdes et en polyphénols ont été analysées sur des fèves de cinq clones de cacao et de leurs descendants issus des croisements réciproques afin de déterminer l'hétérosis et l'héritabilité de ces métabolites. Les alcaloïdes et les polyphénols ont été analysés par HPLC à $280 \mathrm{~nm}$ utilisant un détecteur à barrettes de photodiode (PDA) alors que les anthocyanines l'ont été sur une colonne SEP-PAK Vac 6cc $1000 \mathrm{mg}$ à 520nm utilisant le PDA. Ces fèves ont des teneurs élevées en alcaloïdes puriques $\left(2,1 \mathrm{et} 8,8 \mathrm{mg} \cdot \mathrm{g}^{-1}\right.$ de caféine et de théobromine respectivement) et en polyphénols ( $25 \mu \mathrm{g} . \mathrm{g}^{-1}$ de catéchine et $2978 \mu \mathrm{g} . \mathrm{g}^{-1}$ d'epicatéchine). Des cinq clones utilisés, SNK16 s'est distingué par des teneurs les plus élevées en caféine, théobromine, catéchine et épicatéchine. De tous les paramètres analysés, les anthocyanines ont montré un niveau d'hétérosis élevé. Les génotypes SNK16 et T79/467 ont présenté une meilleure aptitude à la combinaison et les hybrides issus de leur 
croisement réciproque (F5 et F9) ont présenté une meilleure hétérosis par rapport au meilleur parent. L'utilisation de ces deux clones dans un champ semencier serait très importante pour des industries pharmaceutiques car leur croisement génère des hybrides à haut potentiel en alcaloïdes et en polyphénols. De plus, l'absence d'une différence significative de cyanidine-3-galactoside entre hybrides réciproques suggère que l'héritabilité de ce caractère serait nucléaire contrairement aux alcaloïdes puriques et aux flavan-3-ols dont l'héritabilité serait de nature cytoplasmique.

Mots Clés: Caffein, catechin, Theobroma cacao

\section{INTRODUCTION}

Cocoa (Theobroma cacao L.) is an important allogamous tropical tree crop, whose centre of diversity is considered to be in Central America. Three major cultivated types can be distinguished as Criollos, Forasteros and Trinitarios. Criollo is considered to exhibit one of the best flavour qualities; while Trinitario is a hybrid between Criollos and Forasteros; or an intermediate type.

Theobroma cacao beans constitute an important ingredient in different kinds of foods such as cakes, biscuits, child-foods, ice-creams and sweets. It constitutes an inexpensive fat source and is the principal raw material of chocolate (Tafuri et al., 2004).

Cocoa bean is also known to contain the two purine bases, theobromine and caffeine. The relative proportions of these bases have been determined in the mature bean and delipidated dry cocoa powder (Niemenak et al., 2006; Effa et al., 2015).

These compounds exert an excitatory effect on the central nervous system, promote the psychical and physical activities of organisms, stimulate heart and kidney functioning, and inhibit the bronchial muscle tone (Ashihara and Crozier, 2001). Therefore, they are widely used in modern pharmaceutical practice (Temple, 2009).

The major polyphenolic compounds contained in cocoa seeds are catechins (3.0-6.0\%), leucocyanidins $(2.5 \%)$ and tannins $(2.0-3.5 \%)$ (Afoakwa et al., 2012). Flavanols, the most abundant flavonoids in cocoa, comprise the monomeric flavanols, (+)-catechin and (-)epicatechin, and their oligomeric and polymeric forms (procyanidins). (-)-Epicatechin has been reported as the major monomeric flavanol in cocoa, representing $35 \%$ of the total phenolic content (Wollgast et al., 2000). These compounds are associated with a decrease in low-density lipoprotein (LDL) oxidation, oxidative stress, platelet activation, platelet function, and an increase in high-density lipoprotein (HDL) concentration, antioxidant status, and NO bioactivity, together with an improvement in endothelial function (Andres-Lacueva et al., 2008).

Intercrossing different varieties of plants frequently produces hybrid offsprings with superior vigour and increased yields, in a poorly understood phenomenon known as heterosis. Two types of heterosis have been considered (Hochholdinger and Hoecker, 2007). The first type refers to the phenomenon in which the hybrid $\mathrm{F}_{1}$ offsprings exhibit phenotypic characteristics that are superior to the mean of the two parents (midparent heterosis). The second, the better of the two parents (best parent heterosis) indicates that a hybrid trait performs significantly better than the better of the two homozygous parental inbred lines.

Heterosis has been extensively exploited in plant breeding, particularly in maize (Sultan $e t$ al., 2014; Hochholdinger and Hoecker, 2007; Fernandez-Silva et al., 2009), fertility, resistance to disease and to insect pest, or to climatic rigours (Rhode et al., 2004; Korn et al., 2008). Despite the fact that purine alkaloids and flavanols are signature component in cocoa beans, little information is available on heterosis of these traits in cocoa.

Another important genetic factor used by breeders is heritability. This term denotes the proportion of genetically controlled variability and is a very important biometrical tool for guiding plant breeder for the adoption of appropriate breeding procedures. Springer and Robert (2007) partitioned it as very high (>90\%), high (70-90\%) medium (50-70\%) and low $(<50 \%)$. Heritability, however, indicates only the effectiveness with which selection of genotype 
can be based on phenotypic performance, but fail to indicate the genetic progress. Heritability estimates along with genetic gains are more effective and reliable in predicting improvement through selection. Estimates of genetic advance predict the extent of improvement that can be achieved for improving the different characters.

Heritability of biochemical metabolites in the Theobroma cacao/Phythophthora megakarya interaction has been studied by many authors. Some of these authors stated that the relationship between phenolic compounds, amino acids, carbohydrates and resistance to Phytophthora megakarya in T. cacao detected no maternal effect in the transmission of these characters (Djocgoue et al., 2011; Ondobo et al., 2013). As for heterosis, little information is available on heritability of purine alkaloids and flavanols in cocoa.

The objective of this study was to estimate heterosis and broad-sense heritability of cocoa purine alkaloids, flavanols and cyanidins and to determine the relationships of traits in the $F_{1}$ generation of height crosses under the same environmental condition in Cameroon.

\section{MATERIALS AND METHODS}

Plant materials. Five cocoa clones: two local Trinitario (SNK16 and SNK413), one Trinitario introduced from Trinidad (ICS40), and two Forestero (Sca12 and T79/467) available in gene banks of the Cameroon Cocoa Development Corporation (SODECAO) at Mengang Station (South Cameroon), were used to create eight progenies. Crossings were realised in Mengang Station of SODECAO in May, June and July 2012, using hand-pollination techniques (Cilas, 1991) (Table 1).

Post-harvest treatment. One thousand ripe cocoa pods from different parental cocoa clones and hybrids were harvested from the experimental plots of the SODECAO at Mengang Station. The ripe pods were split and beans obtained were fermented using the traditional heap method (Afoakwa et al., 2012). The fermentation was done by heaping the extracted cocoa beans on the fermenting platform, covered with banana leaves. The heaped beans were again covered with banana leaves and fermented for six days, with consecutive opening and turnings after every two days. The fermented cocoa beans were then sundried on a bamboo mat for twelve days.

Reagents and standards. Protocatechiuc acid and catechin were obtained from Aldrich and Fluka (Hamburg, Germany). Epicatechin was obtained from Sigma (Hamburg, Germany); while caffeine and theobromine were from Merck (Darmstadt, Germany). Water was purified by a Milli-Q water purification system (Millipore, Bedford, MA, USA). All solvents used were of analytical grade, purchased from Merck (Darmstadt, Germany).

Extraction of polyphenols. Two grammes of dry cocoa beans were milled in $10 \mathrm{ml}$ of $\mathrm{n}$-hexane, for fat removal. Most of the residual seed fat was extracted by flushing the powder with $25 \mathrm{ml} \mathrm{n}$ hexane in a Buchner funnel. The phenolic compounds were extracted by agitating $500 \mathrm{mg}$ of the fat-free sample on ice three times with 50 $\mathrm{ml}$ of $60 \%$ aqueous acetone with constant shaking. Each round of shaking was followed by

TABLE 1. General description of cocoa crossings evaluated for heterosis and heritability at Mengang SODECAO Station in South Cameroon

\begin{tabular}{|c|c|c|c|}
\hline Family & Crossings & Family & Back-crossings \\
\hline F5 & () SNK16 $\times\left(\delta^{\pi}\right)$ T79/467 & F9 & (ㅇ) T79/467 × (ठ') SNK16 \\
\hline $\mathrm{F} 70$ & ( & $\mathrm{F} 30$ & $(q)$ SNK413 $\times\left(\delta^{n}\right)$ T79/467 \\
\hline F10 & ( ㅇ ) SCa12 × ( ठ ) T79/467 & $\mathrm{F} 80$ & ( q) T79/467 × (ठ') SCa12 \\
\hline F90 & ( $q)$ T79/467 $\times\left(\delta^{n}\right)$ ICS40 & F95 & $(q)$ ICS40 $\times\left(\delta^{n}\right) T 79 / 467$ \\
\hline
\end{tabular}


centrifugation at $5000 \mathrm{rpm}$, for $15 \mathrm{~min}$, at room temperature. The three supernatants were combined in a flask containing $2 \mathrm{ml}$ of glacial acetic acid. Acetone was removed by rotary evaporation under a partial vacuum at $40^{\circ} \mathrm{C}$. The aqueous phase obtained was adjusted to $100 \mathrm{ml}$ with Milli-Q Plus water in a volumetric flask. The total content in polyphenolic compounds was analysed from this aqueous phase.

For qualitative determination of polyphenols, $50 \mathrm{mg}$ of dry cocoa beans was blended in $3 \mathrm{ml}$ pure $\mathrm{MeOH}$. The homogenate was agitated on ice for $15 \mathrm{~min}$ and centrifuged at $5000 \mathrm{rpm}$ for 10 min. For each sample, extraction was done three times and the extracts were combined and concentrated by rotary evaporation. The dried polyphenolic compounds were resuspended in $1.5 \mathrm{ml}$ pure methanol (Lichrosolv, Merck), and filtered with Millipore paper $(0.45 \mu \mathrm{m})$. The pure polyphenolic extracts were stored at $-20{ }^{\circ} \mathrm{C}$ until analysed by HPLC.

Purification of anthocyanins was conducted from the $100 \mathrm{ml}$ aqueous phase, using a SepPaksVac C18 6cc column (Waters). The column was first eluted with a mixture of pure methanol (10 $\mathrm{ml}): 2 \%$ acetic acid (10 ml). A $20 \mathrm{ml}$ aliquot of the aqueous phase sample was loaded onto the column and washed with $2.5 \mathrm{ml}$ of $2 \%$ acetic acid. Anthocyanins were then eluted twice from the column, with $5 \mathrm{ml}$ pure methanol analytical grade (Lichrosolv, Merck). The eluted fractions were combined and dried by rotary evaporation. The residues were re-suspended in $2 \mathrm{ml}$ of a mixture of pure methanol and $2 \%$ acetic acid.

Analysis of polyphenolic, anthocyanin compounds and purine alkaloids. Total contents of polyphenolic compounds were determined by the Folin-Ciocalteu procedure (Singleton and Rossi, 1965). Chromatographic analyses were carried out on Waters HPLC system equipped with an A2-200 automatic injector and Waters 996 Photodiode Array Detector (PDA). Separation of polyphenols was performed on a LicroCart 250-4 octadecylsilyl (ODS) C18, $5 \mu \mathrm{m}$ particle [RP-18 (5 ìm) ] column (Merck) at $26^{\circ} \mathrm{C}$. The guard column consisted of a LicroCard 4-4 Lichrospher 100 RP$18(5 \mu \mathrm{m})$ (Merck). The binary mobile phase consisted of $2 \%$ acetic acid in water (A) and acetonitrile-water concentrated acetic acid mixture $(4: 9: 1 \mathrm{v} / \mathrm{v} / \mathrm{v})(\mathrm{B})$. Twenty microlitres of sample were injected into the column and polyphenol was detected at $280 \mathrm{~nm}$; while anthocyanins were recorded at $520 \mathrm{~nm}$, using a PDA detector. The identification of each peak was confirmed by a comparison of retention and coelution time with authentic standards of protocatechiuc acid, catechinhydrate, epicatechin, caffeine, theobromine, cyanidin-3galactoside and cyanindin-3-arabinoside.

Statistical analyses. Data were subjected to analysis of variance and multiple range test (LSD) using the Statistical Package for the Social Sciences (SPSS) 18.0 Software for Windows. Principal component analysis (PCA) was performed to establish associations among variables, using the SPAD 5.5 Statistical Software Package. Cluster analyses with polyphenols and alkaloids, using the unweighted pairwise group methods with arithmetical average (UPGMA) on the basis of Nei's (1978) genetic distance, were performed with the assistance of SPAD 5.5.

Heterosis -The methods for calculating heterosis were as follows:

Mid-parent heterosis $(\mathrm{MPH})=[\mathrm{F} 1-\mathrm{MP}] \times 100 / \mu$

Best-parent heterosis $(\mathrm{BPH})=[\mathrm{F} 1-\mathrm{BP}] \times 100 / \mu$

Where: $\mathrm{F} 1=$ hybrid value; $\mathrm{MP}=$ the mid-parent value of both parents; $\mathrm{BP}=$ value of the better parent and $\mu=$ average value of all parents and F1 combinations in the factorial mating design.

To investigate possible heterosis of purine alkaloids and flavanol in cocoa beans, we performed reciprocal crosses between the five parental clones studied. Theoretically, if a heterozygous dominance effect is greater than the mean parental homozygous effects for a cross, a positive middle-parent (MP) heterosis would be expected; otherwise, a negative MP heterosis would be expected (Zhu, 1993; McCarty et al., 2007; Wu et al., 2010).

Heritability-Broad-sense heritability $\left(\mathrm{h}^{2}{ }_{\mathrm{bs}}\right)$ estimates of each cross based were calculated for traits related to secondary metabolites (purine alkaloids and polyphenols), using the following relationships: 
$\mathrm{Vp}=\mathrm{V}_{\mathrm{G}}+\mathrm{V}_{\mathrm{E}}$

$\mathrm{h}_{\mathrm{bs}}^{2}=\mathrm{V}_{\mathrm{G}} / \mathrm{V}_{\mathrm{G}}+\mathrm{V}_{\mathrm{E}}$

$\mathrm{h}_{\mathrm{bs}}^{2}=\left[\mathrm{V}_{\mathrm{F} 1}-\left(\mathrm{V}_{\mathrm{P} 1}+\mathrm{V}_{\mathrm{P} 2}\right) / 2\right] / \mathrm{V}_{\mathrm{F} 1}$

Where: $\mathrm{V}_{\mathrm{F} 1}=$ variance of any cross; $\mathrm{V}_{\mathrm{P} 1}=$ variance of female parent and $\mathrm{V}_{\mathrm{P} 2}=$ variance of male parent. Estimation of environmental variance $\left(\mathrm{V}_{\mathrm{E}}\right)$ for any cross was calculated as $\left(\mathrm{V}_{\mathrm{P} 1}+\mathrm{V}_{\mathrm{P} 2}\right) / 2$. In each cross, variances between $\mathrm{F} 1$ and parents were obtained from the analysis of variance following a completely randomised design, assigning replication as classes.

Genetic correlations $(\mathrm{G})$ among biochemical traits were calculated using the equation described by Zeng et al. (2007):

$\mathrm{G}=\sigma_{\mathrm{gxy}} /\left(\sigma_{\mathrm{gx}}^{2} \sigma_{\mathrm{gy}}^{2}\right)^{1 / 2}, \sigma_{\mathrm{gx}}^{2}=1 / \mathrm{r}\left(\mathrm{V}_{\mathrm{x}}-\mathrm{V}_{\mathrm{ex}}\right)$

$\sigma_{\mathrm{gy}}^{2}=1 / \mathrm{r}\left(\mathrm{V}_{\mathrm{y}}-\mathrm{V}_{\mathrm{ey}}\right), \sigma_{\mathrm{gxy}}=1 / \mathrm{r}\left(\mathrm{Cov}_{\mathrm{xy}}-\mathrm{Cov}_{\mathrm{exy}}\right)$

Where: $\sigma_{g x y}$ is the genetic component of covariance between variable $\mathrm{x}$ and $\mathrm{y} ; \sigma_{\mathrm{gx}}^{2}$ and $\sigma_{\mathrm{gy}}^{2}$ are genetic components of variance for $\mathrm{x}$ and $\mathrm{y}$, respectively; $\mathrm{Vx}$ and $\mathrm{Vy}$ are variances of $\mathrm{x}$ and $y$, respectively; Vex and Vey are errors for $\mathrm{x}$ and $\mathrm{y}$, respectively; $r$ is the number of replicates.

\section{RESULTS}

Hand-pollination test was better in F30 and F80 families, with the percentage of success of 39 and 23, respectively (Table 2). These results were less successful in F95 (13\%) and F5 (11\%) families.

Caffein, theobromin, catechin, epicatechin, cyanidin-3-galactoside and cyanidin-3arabinoside contents in defatted cocoa powder were determined by HPLC analysis (Table 3 ). Cocoa beans were rich in purine alkaloid (2.1 and $8.8 \mathrm{mg} \cdot \mathrm{g}^{-1}$ for caffein and theobromine, respectively) and theobromin was four-folds higher than caffein content $\left(2.14 \mathrm{mg} \mathrm{g}^{-1} \mathrm{DCP}\right.$ on average).

Among the five cocoa clones, SNK16 was highest in purine alkaloid (caffein and theobromin) and flavanol (catechin and epicatechin) contents; while T79/467 possessed the greatest quantity of cyanidin-3-galactoside and cyanidin-3arabinoside (Table 3). According to multiple comparison tests, hybrids for groups 1 and 4 displayed caffein values similar to those of their parents. For theobromin, none of the parents presented comparable value compared to that of their offsprings.

Epicatechin was the most abundant monomeric flavanol in cocoa powder (Table 3).

TABLE 2. Rate of success of hand-pollination of cocoa in a heterosis and heritability study at Mengang SODECAO Station in South Cameroon

\begin{tabular}{|c|c|c|c|c|c|}
\hline Groups & Families & Crossings & Number of test & $\begin{array}{l}\text { Number of } \\
\text { successes }\end{array}$ & $\begin{array}{c}\text { Percentage of } \\
\text { success }\end{array}$ \\
\hline & F5 & (ㅇ) SNK16 × ( $\left.\sigma^{\pi}\right)$ T79/467 & 500 & 55 & 11 \\
\hline \multirow[t]{2}{*}{1} & F9 & $\left(q\right.$, T79/467 $\times\left(\delta^{2}\right)$ SNK16 & 500 & 90 & 18 \\
\hline & F70 & $\left(\phi\right.$, T79/467 $\times\left(\delta^{n}\right)$ SNK413 & 500 & 80 & 16 \\
\hline \multirow[t]{2}{*}{2} & F30 & $(q)$ SNK413 $\times\left(\delta^{n}\right)$ T79/467 & 500 & 195 & 39 \\
\hline & F10 & ( Q ) SCa12 × ( $\left.\delta^{\prime}\right) \mathrm{T} 79 / 467$ & 500 & 105 & 21 \\
\hline \multirow[t]{2}{*}{3} & F80 & ( 9 ) T79/467 × (ठ̊) SCa12 & 500 & 115 & 23 \\
\hline & F90 & ( & 500 & 75 & 15 \\
\hline 4 & F95 & (o) $)$ ICS40 x ( o ) T79/467 & 500 & 65 & 13 \\
\hline
\end{tabular}


TABLE 3. Caffein, theobromin, catechin, epicatechin, cyanidin-3-galactoside and cyanidin-3- arabinoside contents in defatted cocoa powder (DCP) determined by HPLC analysis

\begin{tabular}{|c|c|c|c|c|c|c|c|}
\hline \multirow[t]{2}{*}{ Group } & \multirow[t]{2}{*}{ Clone } & \multicolumn{2}{|c|}{ Purine alkaloids ( $\mathrm{mg} \mathrm{g}^{-1}$ ) } & \multicolumn{2}{|c|}{ Flavan-3-ol $\left.(\mu \mathrm{g} \mathrm{g})^{-1}\right)$} & \multicolumn{2}{|c|}{ Cyanidins ( $\left.\mu \mathrm{g} \mathrm{g} \mathrm{g}^{-1}\right)$} \\
\hline & & Caffein & Theobromin & Catechin & Epicatechin & $\begin{array}{l}\text { Cyanidin-3- } \\
\text { galactoside }\end{array}$ & $\begin{array}{l}\text { Cyanidin-3- } \\
\text { arabinoside }\end{array}$ \\
\hline & SNK16 & $3.27 f$ & $13.42 d$ & $75.57 g$ & $4551.7 \mathrm{~g}$ & $166.05 d$ & $446.24 \mathrm{~g}$ \\
\hline \multirow[t]{4}{*}{1} & T79/467 & $2.46 \mathrm{~d}$ & $10.09 c$ & 24.81d & $3423.6 \mathrm{e}$ & $244.90 \mathrm{~g}$ & $599.20 \mathrm{~h}$ \\
\hline & F5 & $2.97 e$ & $12.20 \mathrm{c}$ & $47.27 f$ & $4136.9 f$ & $226.25 f$ & $575.20 \mathrm{~h}$ \\
\hline & F9 & $3.11 \mathrm{e}$ & $12.76 \mathrm{c}$ & $29.18 \mathrm{e}$ & $4328.1 f$ & $278.57 \mathrm{~h}$ & $774.50 \mathrm{i}$ \\
\hline & T79/467 & $2.46 \mathrm{~d}$ & $10.09 c$ & 24.81d & $3423.6 \mathrm{~d}$ & $244.90 \mathrm{~g}$ & $599.20 \mathrm{~h}$ \\
\hline \multirow[t]{4}{*}{2} & SNK413 & $1.01 \mathrm{a}$ & $4.13 a$ & $11.49 a$ & $1403.2 a$ & $26.31 \mathrm{a}$ & $78.25 a$ \\
\hline & $\mathrm{F} 70$ & $1.64 b$ & $6.74 b$ & $12.39 a$ & $2285.9 \mathrm{C}$ & $163.12 d$ & $421.65 f$ \\
\hline & F30 & $1.68 b$ & $6.89 \mathrm{~b}$ & $14.70 b$ & $2335.9 \mathrm{c}$ & $191.12 \mathrm{e}$ & $418.05 f$ \\
\hline & Sca12 & $2.08 \mathrm{c}$ & $8.53 b$ & 23.37d & $2894.4 d$ & $84.4 b$ & $252.29 \mathrm{c}$ \\
\hline \multirow[t]{4}{*}{3} & T79/467 & $2.46 \mathrm{~d}$ & $10.09 c$ & 24.81d & $3423.6 \mathrm{e}$ & $244.90 \mathrm{~g}$ & $599.20 \mathrm{~h}$ \\
\hline & F10 & $1.69 b$ & $6.93 b$ & $20.08 \mathrm{c}$ & $2350.3 \mathrm{c}$ & $146.55 \mathrm{~d}$ & $343.94 \mathrm{e}$ \\
\hline & F80 & $1.47 b$ & $6.04 b$ & $13.41 a$ & $2050.3 b$ & $116.55 \mathrm{c}$ & $305.05 d$ \\
\hline & ICS40 & $2.16 \mathrm{c}$ & $8.85 b$ & $24.58 d$ & $3001.8 d$ & $25.68 a$ & $163.95 b$ \\
\hline \multirow[t]{5}{*}{4} & T79/467 & $2.46 \mathrm{~d}$ & $10.09 c$ & 24.81d & $3423.6 \mathrm{e}$ & $244.90 \mathrm{~g}$ & $599.20 \mathrm{~h}$ \\
\hline & F90 & $2.10 c$ & $8.60 \mathrm{~b}$ & $11.93 a$ & $2916.8 d$ & $201.35 \mathrm{e}$ & $456.8 \mathrm{~g}$ \\
\hline & F95 & $2.18 c$ & $8.95 b$ & $15.26 \mathrm{~b}$ & $3036.8 \mathrm{c}$ & $227.35 f$ & $496.8 \mathrm{~g}$ \\
\hline & Means & 2.14 & 8.79 & 24.93 & 2978.20 & 161.40 & 410.43 \\
\hline & Sums & 27.88 & 114.21 & 324.09 & 38716.58 & 2098.24 & 5335.57 \\
\hline
\end{tabular}

Means with the same letter are not significantly different at the 0.05 probability level as calculated by the Tukey's test within the respective trial

Flavan-3-ol cocoa beans content displayed that epicatechin with an average of $29.8 \mathrm{mg} \mathrm{g}^{-1} \mathrm{DCP}$ was 100 -folds higher than catechin $\left(0.29 \mathrm{mg} \mathrm{g}^{-1}\right.$ DCP). For catechin and in group 2, F30 and F70 hybrids showed values not significantly different to their SNK413 parent. In the same way, catechin content of T79/467 and SNK413 clones were similar to their F10 offspring. Group 4 is special for epicatechin since F90 and F95 hybrids displayed the same value with ICS40 parental clone.

Cyanidin-3-arabinoside was about three-folds higher than cyanidin-3-galactoside, and the two main anthocyanins found in our samples represented about $6 \%$ of defatted cocoa seed powder. As for the cyanidin 3-O- $\beta$-D-galactoside, a variation between 25.68 and $278.57 \mu \mathrm{g} \mathrm{g}^{-1}$ defatted cocoa was found, whereas the content of cyanidin 3-O- $\alpha$-L-arabinoside ranged from 78.25 to $774.5 \mu \mathrm{g} \mathrm{g}^{-1}$.

Heterosis analysis. Table 4 summarises the results of Mid-parent heterosis (MPH) and Bestparent heterosis $(\mathrm{BPH})$ of hybrids derived from the crossing of five cocoa clones.

F5 and F9 hybrids distinguished themselves from other hybrids by the fact that they show positive MPH to five of six traits, except for catechin where they displayed a negative MPH. Contrary to other offsprings, F10 and its reciprocal F80 showed a negative MPH for all traits. Negative mid-parent heterosis was detected for four of the six traits except Cyanidin-3Galactoside and Cyanidin-3-Arabinoside. For $\mathrm{BPH}$, all hybrids presented a negative BPH except F9 individual which presented a low positive $\mathrm{BPH}$ 
for cyanidin compounds (Table 4). In terms of Best-parent heterosis, no positive BPH was observed for all the six traits (Table 5).

Heritability. Broad-sense heritability for traits related to purine alkaloids and polyphenols were evaluated in the F1 population (Table 6).

The heritability estimates for theobromin were low to moderate, ranging from 0 to 0.80 , with an average of 0.27 (Table 6). For purine alkaloids, the heritability estimate of F90 hybrid was zero. This value was near to zero for F5 (theobromin), F30 (catechin) and for F95 individual (theobromin and catechin).

Analysis of variation in the sample was visualised in the Principal Component Analysis (Fig. 1). The two first Principal Components generated from all the data represented $94.24 \%$ of the total variability. Caffein, epicatechin, theobromin and cyaniding-3-arabinoside were the dominating features in the first Principal Component (74.16\% of the total variability); while catechin and cyaniding-3-galactoside were the features with the highest weight in the second principal component $(20.08 \%$ of the total variability).

Additionally, correlations among these traits at genotypic and phenotypic levels are given in Table 7. All traits showed significant genotypic and phenotypic correlations, except Cyanidin-3Galactoside and catechin.

Dendrogram generated by the unweight pair group (UPGMA) permitted a better visualisation of the distribution (Fig. 2). Considering the distance of D 1.0, the cluster generated four groups. The first group with three individuals (SNK16, F5 hybrid and his reciprocal F9), was dominated by high amounts of purine alkaloids and flavan-3-ol. The second group consisted of all parental clones, except SNK16, and distinguished itself by low amounts of cyaniding3-galactoside and cyaniding-3-arabinoside. The third group included T79/467 parental clone and hybrids, obtained with its cross with ICS40 counterpart (F90 and F95) and was characterised by average amounts of all metabolites. Group four, more polymorphic, contained four hybrids belonging to two different families were characterised by low amounts of purine alkaloids. 
TABLE 5. The heterosis over mid-parent or better parent of six secondary compounds of cocoa hybrids raised at Mengang SODECAO Station in South Cameroon

\begin{tabular}{|c|c|c|c|c|c|c|c|c|}
\hline \multirow{2}{*}{$\begin{array}{l}\text { Property/ } \\
\text { subsistance }\end{array}$} & \multicolumn{4}{|c|}{ MPH } & \multicolumn{4}{|c|}{$\mathrm{BPH}$} \\
\hline & Average & Range & $+\mathrm{N}$ & $-\mathrm{N}$ & Average & Range & $+\mathrm{N}$ & $-\mathrm{N}$ \\
\hline Caffein & $-8,97$ & -35.2 to 8.8 & 2 & 6 & $-22,31$ & -40.2 to -4.7 & 0 & 8 \\
\hline Theobromin & $-8,92$ & -35.1 to 8.5 & 2 & 6 & $-22,06$ & -40.1 to -4.9 & 0 & 8 \\
\hline Catechin & $-31,16$ & -51.7 to -5.8 & 0 & 8 & $-43,08$ & -61.4 to -19.1 & 0 & 8 \\
\hline Epicatechin & $-8,95$ & -35.3 to 8.7 & 2 & 6 & $-22,07$ & -40.3 to -4.7 & 0 & 8 \\
\hline Cya.-3-Gal. & 22,95 & -29.2 to 68.0 & 6 & 2 & $-19,83$ & -52.4 to 0.1 & 1 & 7 \\
\hline Cya.-3-Ara. & 13,69 & -28.3 to 48.2 & 6 & 2 & $-20,77$ & -49.1 to 0.3 & 1 & 7 \\
\hline
\end{tabular}

$\mathrm{MPH}=$ Mid-parent heterosis based on population mean; $\mathrm{BPH}=$ Best-parent heterosis based on population mean; $+\mathrm{N}=$ number of combinations with positive heterosis; $-\mathrm{N}=$ number of combinations with negative heterosis

TABLE 6. Broad-sense heritability estimates for some secondary metabolites in four crossings and reciprocal of cocoa raised at Mengang SODECAO Station in South Cameroon

\begin{tabular}{lcccccc}
\hline Hybrids & Caffein & Theobromin & Catechin & Epicatechin & Cya-3-Gal & Cya-3-Ara \\
\hline F5 & 0.86 & 0.07 & 0.72 & 0.92 & 0.99 & 0.54 \\
F9 & 0.11 & 0.15 & 0.19 & 0.60 & 0.71 & 0.68 \\
F70 & 0.86 & 0.80 & 0.43 & 0.34 & 0.88 & 0.49 \\
F30 & 0.21 & 0.62 & 0.01 & 0.48 & 0.73 & 0.49 \\
F10 & 0.90 & 0.18 & 0.66 & 0.69 & 0.97 & 0.35 \\
F80 & 0.36 & 0.35 & 0.66 & 0.09 & 0.98 & 0.30 \\
F90 & 0.00 & 0.00 & 0.96 & 0.50 & 0.82 & 0.51 \\
F95 & 0.94 & 0.01 & 0.08 & 0.58 & 0.80 & 0.56 \\
Mean & 0.53 & 0.27 & 0.46 & 0.52 & 0.86 & 0.49 \\
\hline
\end{tabular}

TABLE 7. Genotypic $(G)$ and phenotypic $(P)$ correlation coefficients among six biochemical components of cocoa raised at Mengang SODECAO Station in South Cameroon

\begin{tabular}{|c|c|c|c|c|c|c|c|}
\hline Subsistance & & Caffeine & Theobromin & Catechin & Epicatechin & Cya-3-gal. & Cya-3-ara. \\
\hline \multirow[t]{2}{*}{ Theobromin } & G & $0.93^{*+*}$ & & & & & \\
\hline & $P$ & $0.79^{* *}$ & & & & & \\
\hline \multirow[t]{2}{*}{ Catechin } & G & $0.80^{*+}$ & $0.74^{* *}$ & & & & \\
\hline & $P$ & $0.80^{*+}$ & $0.72^{*+*}$ & & & & \\
\hline \multirow[t]{2}{*}{ Epicatechin } & G & $0.93^{*+*}$ & $0.86^{* *}$ & $0.70^{* *}$ & & & \\
\hline & $P$ & $0.99^{*+}$ & $0.79^{*+}$ & $0.79^{* *}$ & & & \\
\hline \multirow[t]{2}{*}{ Cya-3-gal. } & G & $0.59^{* *}$ & $0.45^{*}$ & 0.19 & $0.67^{*+}$ & & \\
\hline & $P$ & $0.57^{*}$ & $0.42^{*+*}$ & 0.21 & $0.59^{* *}$ & & \\
\hline \multirow[t]{2}{*}{ Cya-3-ara. } & G & $0.71^{* *}$ & $0.58^{* *}$ & $0.29^{*}$ & $0.79^{* *}$ & $0.97^{\prime \prime}$ & \\
\hline & $P$ & $0.70^{* *}$ & $0.48^{* *}$ & $0.32^{*}$ & 0.72 & $0.96^{* \prime}$ & 1 \\
\hline
\end{tabular}

Significant at ${ }^{*} 0.05$ and ${ }^{* *} 0.01$ probability level, respectively 
Principal component $2-20.68 \%$

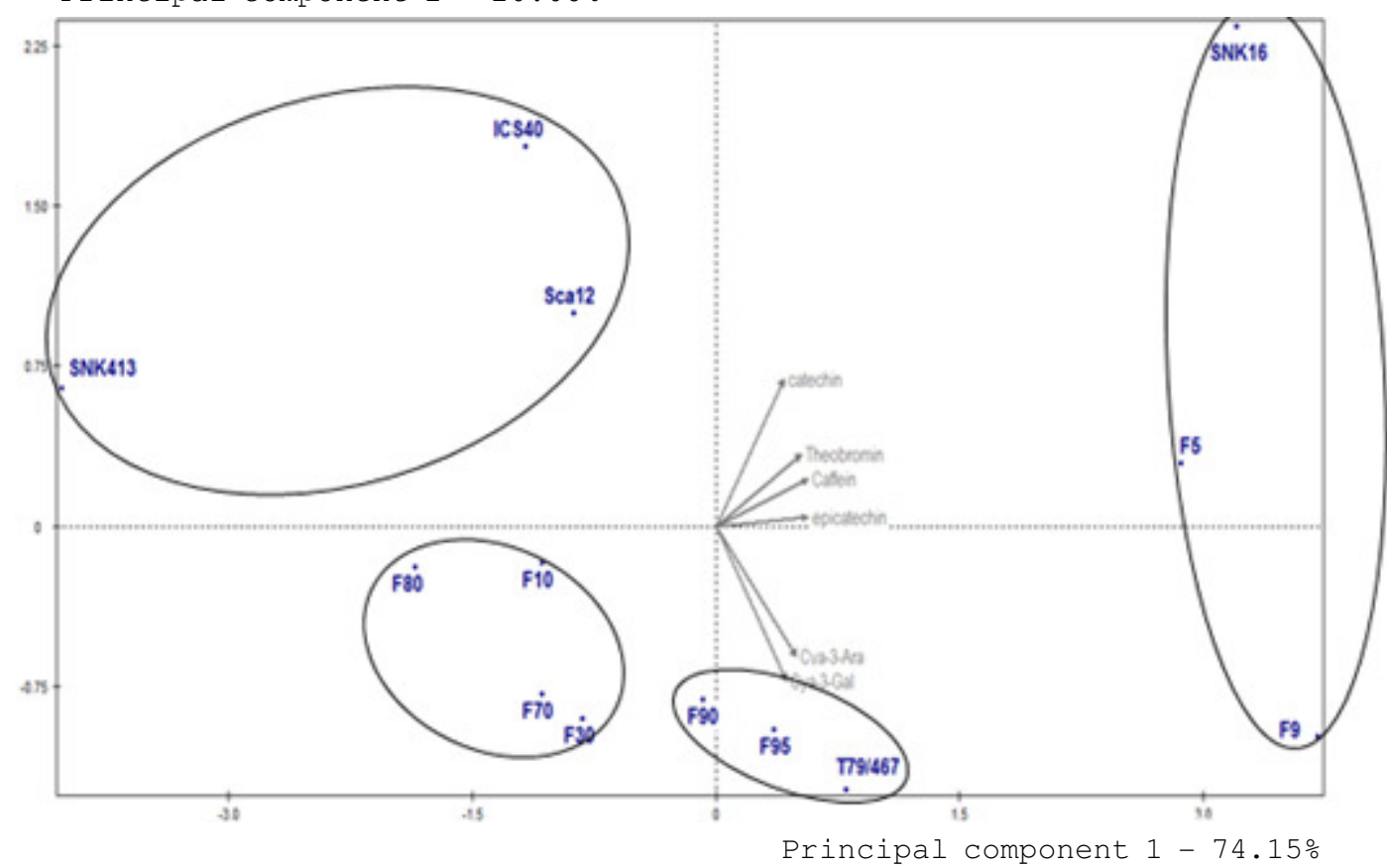

Figure 1. Loading plot of the first two principal components for caffein, theobromin, catechin, epicatechin, cyanidin-3-galactoside and cyanidin-3- arabinoside contents in defatted cocoa powder (DCP) determined by HPLC analysis.

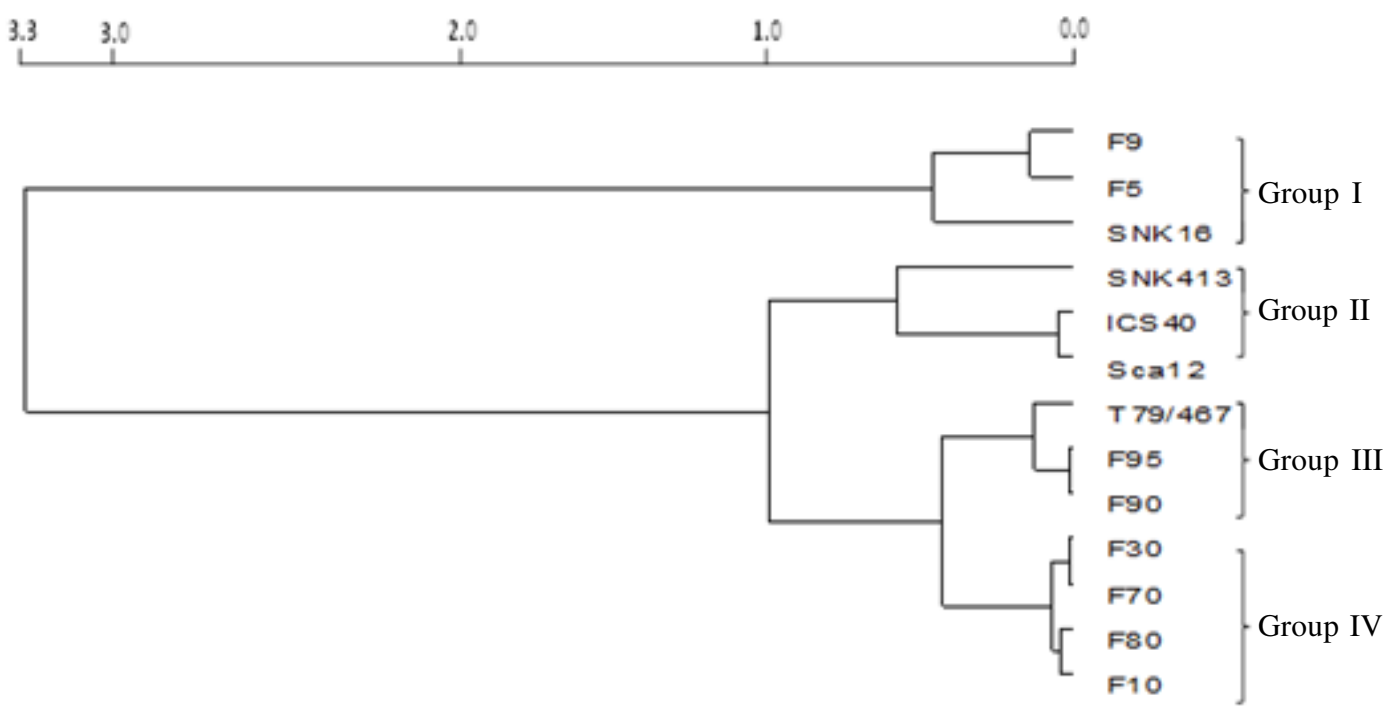

Figure 2. Dendrogram of cocoa clones and their offspring's generated by unweight pair group method (UPGAM) based on hierarchical cluster analysis using data on purine alkaloids, flavanols and cyanidins. 


\section{DISCUSSION}

Analysis of purine alkaloids in cocoa beans in our study showed that theobromin was fourfolds higher than caffein content. This result is in agreement with those obtained by many authors (Pura, 2001; Effa et al., 2015), who confirmed that theobromin is the dominant purine alkaloid present in cocoa beans. As expected, this study revealed that epicatechin was the most abundant monomeric flavanol in cocoa beans. Andres-Lacueva et al. (2008) also found that natural cocoa presented content of total flavonoids, equivalent to $2.65 \mathrm{mg} \mathrm{g}^{-1}(-)-$ epicatechin, representing the highest proportion. Recently, Tomas-Barberan et al. (2007) reported (+)-catechin values of 6.46 and $2.02 \mathrm{mg} \mathrm{g}^{-1}$ and (-)-epicatechin values of 25.65 and $3.30 \mathrm{mg} \mathrm{g}^{-1}$ for a polyphenol-rich and a conventional cocoa powder, respectively. Besides flavonoids, anthocyanin components were also detected in samples and the two main anthocyanins found (cyanidin-3-arabinoside and cyanidin-3galactoside) represented about $6 \%$ of defatted cocoa seed powder. These values were similar to those obtained by Effa et al. (2015) in defatted cocoa powder and lower than those obtained by Elwers et al. (2009) in cocoa seeds. For the last authors, the difference could be due to variation in the methods used for the extraction of anthocyanins.

There was variation in the relative level of heterosis for different traits between different hybrids. This can be explained by the fact that heterosis is not the result of single locus action; nor does it simply reflect the overall extent of heterozygosity between parents. In fact, according to Springer and Robert (2007), the variation in levels of heterosis among traits leads to difficulties in accurately quantifying the amount of overall heterosis.

F90 hybrid and its reciprocal F95 displayed high value of MPH for cyanidin-3-galactoside. Furthermore, the parental genotypes (T79/467 and ICS40) showed good aptitudes for combination and their introduction into the biclonal planting field will be important for providing hybrids with high cyanidin attributes.

Hybrids derived from SNK16 and T79/467 clones (F5 and F9) exhibited low MPH and BPH for alkaloids and flavan-3-ols; while the genetic distance between their parents was low ( D 0.5). In fact, as the genetic distance between parental inbreds increases, there is generally an increase in heterosis; yet when the parental distance exceeds a threshold, heterosis decreases. Thus, there appears to be a relationship between genetic diversity and heterosis; however, the correlation is not strong enough to be used as an accurate predictive tool (Melchinger, 1999).

The heritability estimates for some traits were high, especially for cyanidin-3-galactoside and cyanidin-3-arabinoside where the value of the heritability was superior or equal to 0.3 for all hybrids. According to Nair et al. (2012), a high value of heritability in broad sense indicates that, though the character is least influenced by the environmental effects, the selection for improvement of such character may be useful, because broad sense heritability is based on total genetic variance which includes both fixable (additive) and non fixable (dominance and epistatic) variances. The absence of significant difference between genotypes coming from reciprocal crossbreeding for cyanidins suggests that transmission of these metabolites in cocoa may be nuclear. In contrast, a significant difference was observed between values of the Broad-sense heritability of caffein contents in all reciprocal crossings, portraying presence of maternal heritability.

Examining a two-dimensional score plot in the space defined by PC1 and PC2, showed that the distribution of samples followed a pattern. SNK16 parental clone and its offsprings contained large amounts of caffeine, theobromine, catechin and epicatechin, thus PC1 clearly separates them from the other samples. Corresponding estimates of genotypic correlation coefficients were approximately equal to phenotypic correlation coefficients. The existence of positive correlations among components measured suggests that these traits can be simultaneously improved.

\section{CONCLUSION}

Dry cocoa beans display high contents of purine alkaloids and polyphenols. Theobromin content in cocoa beans is four-folds higher than caffeine content. Anthocyanins (Cyanidin-3-galactoside 
and cyanidin-3-arabinoside) present the highest level of heterosis. Parental genotypes SNK16 and T79/467 show good aptitudes for the combination of the characters since their reciprocal hybrids $\mathrm{F} 5$ and $\mathrm{F} 9$ distinguished themselves by better level of mid-parent heterosis value. These two clones could be interesting for drug industries, and their introduction into the biclonal planting field will be important. Furthermore to the Principal component analysis, corresponding estimates of genotypic correlation coefficients are approximately equal to phenotypic correlation coefficients. Besides, the heritability value in the strict sense of this Cyanidin-3-galactoside is very high. The absence of significant difference between genotypes coming from reciprocal crossbreeding for Cyanidin-3-galactoside suggests that this character in cocoa would be nuclear contrary to purine alkaloids and flavan-3-ols where their transmission to offsprings can be stated as cytoplasmic.

\section{ACKNOWLEDGEMENT}

The authors thank the Cameroon Cocoa Development Corporation (SODECAO) for the field used. Sincere gratitude goes to the Mengang staff for assistance over several years.

\section{REFERENCES}

Afoakwa, E.O., Quao, J., Takrama, F.S., Budu, A. S. and Saalia, F.K. 2012. Changes in total polyphenols, o-diphenols and anthocyanin concentrations during fermentation of pulp pre-conditioned cocoa (Theobroma cacao) beans. International Food Research Journal 19(3):1071-1077.

Andres-Lacueva, C., Monagas, M., Khan, N, Izquierdo-Pulido, M., Urpi-Sardam, M., Permanyerm, J. and Lamuela-Raventos, R.M. 2008. Flavanol and flavonol contents of cocoa powder products: Influence of the manufacturing process. Journal of Agricultural and Food Chemistry (56):31113117.

Ashihara, H. and Crozier, A. 2001. Caffeine: A well-known but little mentioned compound in plant science. TRENDS in Plant Science 6 (9):407 - 413.

Cilas, C. 1991. Estimation of some genetics parameters of different crosses plans of cocoa. Café Cacao Thé (25):3-13.

Djocgoue, P.F., Mbouobda, H.D., Boudjeko, T., Effa, P.O. and Omokolo, N.D. 2011. Amino acids, carbohydrates and heritability of resistance in the Theobroma cacaol Phythophthora megakarya interaction. Phytopathologia Mediterranea (50): 370-383.

Effa, O.P., Niemenak, N., Djocgoue, P.F., Ondobo, M.L. and Omokolo, N.D. 2015. Heritability of polyphenols, anthocyanins and antioxidant capacity of Cameroonian cocoa (Theobroma cacao L.) beans. African Journal of Biotechnology 14(36):2672-2682.

Elwers, S., Zambrano, A., Rohsius, C., Lieberei, R. 2009. Differences between the content of phenolic compounds in Criollo, Forastero and Trinitario cocoa seed (Theobroma cacao L.). European Food Research Technology (229): 937-948.

Fernandez-Silva, I., Moreno, E., Eduardo, I., Arus, P., Alvarez, J.M. and Monforte, A.J. 2009. On the genetic control of heterosis for fruit shape in melon (Cucumismelo L.). Journal of Heredity 100(2):229-235.

Hochholdinger, F. and Hoecker, N. 2007. Towards the molecular basis of heterosis. Trends in Plant Science 12 (9): 427-432.

Korn, M., Peterek, S., Mock, H.P., Heyer, A.G. and Hincha, D.K. 2008. Heterosis in the freezing tolerance, and sugarand flavonoid contents of crosses between Arabidopsis thaliana accessions of widely varying freezing tolerance. Plant Cell and Environment 31(6): 813-827.

McCarty, J.C., Wu, J., Jenkins, J.N. 2007. Use of primitive derived cotton accessions for agronomic and fiber traits improvement: variance components and genetic effects. Crop Science 47:100-110.

Melchinger, A.E. 1999. Genetic diversity and heterosis. In: The genetics and exploitation of heterosis in crops: Coors, J.G. and Pandey, S. (Eds.). American Society of Agronomy, and Crop Science Society of America. pp. 99-118. 
Nair, B., Sengupta, S.K., Naidu, A.K., Mehta, A.K., Singh, K.P. and Jain, P.K. 2012. Assessment of heritability and genetic advance in coriander germplasms. JNKVV Research Journal 46(3):317-321.

Nei, M. 1978. Estimation of average heterozygosity and genetic distance from a small number of individuals. Genetics 89:583590.

Niemenak, N., Rohsius, C., Elwers, S., Omokolo, N.D. and Lieberei, R. 2006. Comparative study of different cocoa (Theobroma cacao L.) clones in terms of their phenolics and anthocyanins contents. Journal of Food Composition and Analysis (19):612-619.

Ondobo, M.L., Effa, O.P., Djocgoue, P.F., Boudjeko, T., Manga, N.J., Djoko, K.J.C. and

Omokolo, N.D. 2013. Influence of Phytophthora megakarya inoculation on necrosis length, phenolic content, peroxidase and polyphenoloxidase activity in cocoa (Theobroma cacao L) plants. Syllabus Science Series Review 4:8-18.

Pura, N.J. 2001. Improved high-performance liquid chromatography method to determine Theobromine and caffeine in cocoa and cocoa products. Journal of Agricultural and Food Chemistry 49:3579-3583.

Rhode, P., Dirk, K.H. and Arnd, H.G. 2004. Heterosis in the freezing tolerance of crosses between two Arabidopsis thaliana accessions (Columbia-O and $\mathrm{C} 24$ that show differences in non- acclimated and acclimated freezing tolerance. The Plant Journal 38:790799.

Singleton, V.L. and Rossi, J.A. 1965. Colorimetric of total phenolics with phosphomolybdicphosphotungstic acid reagents. American Journal of Enology and Viticulture 16:144158.

Springer, N.M. and Robert, M. 2007. Stupar Allelic variation and heterosis in maize: How do two halves make more than a whole? Genome Research 17:264-275.
Sultan, M.S., Abdel-Monaem, M.A. and Haffez, S.H. 2014. Phenotypic and genotypic correlations, heritability andexpected gains from selection for some traits of maize under two plant densities conditions. Asian Journal of Crop Science 6(1):49-57.

Tafuri, A., Ferracane, R. and Ritieni, A. 2004. Ochratoxin A in Italian marketed cocoa products. Food Chemistry 88:487-494.

Temple, J.L. 2009. Caffeine use in children: What we know, what we have to learn and why we should worry. Neuroscience and Biobehavioral Reviews 33:793-806.

Tomas-Barberán, F.A., Cienfuegos-Jovellanos, E., Marín, A., Muguerza, B., Gil-Izquierdo, A., Cerdá, B., Zafrilla, P., Morillas, J., Mulero, J., Ibarra, A., Pasamar, M.A., Ramón, D. and Espín, J.C. 2007. A new process to develop a cocoa powder with higher flavonoid monomer content and enhanced bioavailability in healthy humans. Journal of Agricultural and Food Chemistry 55:3926-3935.

Wollgast, J. and Anklam, E. 2000. Review on polyphenols in Theobroma cacao: Changes indifferent cocoa (Theobroma cacao L.) clones in terms of their phenolics and anthocyanins contents. Journal Food Composition and Analysis 19:612-619.

Wu, J., McCarty, J.C., Jenkins, J.N. and Meredith, W.R. 2010. Breeding potential of introgressions into upland cotton: Genetic effects and heterosis. Plant Breeding 129: 526-532.

Zeng, L., Meredith, W.R. Jr., Boykin, D.L. and Taliercio, E. 2007. Evaluation of an exotic germplasm population derived from multiple crosses among Gossypium tetraploid species. Journal of Cotton Science 11:118127.

Zhu, J. 1993. Methods of predicting genotype value and heterosis for offspring of hybrids. Journal of Biomathematics (Chinese) 8:3244. 